\title{
Bartter-like syndrome caused by kanamycin during therapy for multidrug-resistant Mycobacterium tuberculosis
}

\author{
Mogamat-Yazied Chothia ${ }^{1,4}$, Jan H Esser², Nihal de Vries ${ }^{3}$, Mogamat Razeen Davids ${ }^{4}$ \\ 1,4 Division of General Medicine, Stellenbosch University and Tygerberg Hospital, Cape Town, South Africa; ${ }^{2}$ Department of Chemical \\ Pathology and National Health Laboratory Services, Stellenbosch University and Tygerberg Hospital, Cape Town, South Africa; ${ }^{3}$ Brooklyn

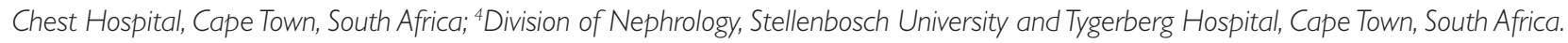

\section{ABSTRACT}

Multidrug-resistant Mycobacterium tuberculosis infection (MDR-TB) is a highly prevalent communicable disease in South Africa and often occurs in those with HIV infection. We describe three HIV-infected patients with pulmonary MDR-TB who received treatment with a regimen that included kanamycin and subsequently developed a Bartter-like syndrome. The clinical presentation varied from asymptomatic to severely symptomatic electrolyte disturbances, with one fatal outcome. This report highlights the importance of the routine monitoring of electrolytes in MDR-TB patients receiving treatment that includes kanamycin.

Keywords: Kanamycin, Bartter-like syndrome, MDR-TB.

\section{BACKGROUND}

This article describes three cases of Bartter-like syndrome caused by kanamycin, an aminoglycoside used for the treatment of multidrug-resistant Mycobacterium tuberculosis infection (MDR-TB). Bartter syndrome is a renal disease characterised by an inability of the thick ascending limb of the loop of Henle (TALH) to reabsorb salt and was first described by Dr F Bartter in 1962 [I]. Consequently, a group of autosomal recessive disorders with the common characteristic of renal salt wasting together with hypokalaemia and metabolic alkalosis was described [2]. Other Bartter-like syndrome phenotypes with similar biochemical abnormalities but without primary renal disease have also been described in cystic fibrosis [3], surreptitious diuretic use [4] and as a complication of the use of chemotherapeutic agents [5].

\section{CASE I}

A 36-year-old female presented with a history of acute worsening of chronic diarrhoea, severe weakness, weight loss and a seizure. She denied having any episodes of vomiting. She had been diagnosed with HIV infection 10 weeks earlier and had a CD4+ T-cell count of 54 cells $/ \mathrm{mm}^{3}$. Six weeks prior to her current presentation, a diagnosis of pulmonary MDR-TB was made, and she was initiated on treatment that included terizidone 750 mg/d, ethionamide $750 \mathrm{mg} / \mathrm{d}$, ofloxacin $800 \mathrm{mg} / \mathrm{d}$, ethambutol $1000 \mathrm{mg} / \mathrm{d}$ and kanamycin $1000 \mathrm{mg} / \mathrm{d}$ intramuscularly (IM). Other medications included the anti-retroviral drugs stavudine, lamivudine and efavirenz. She had no other medical conditions and was not using any other chronic medication such as diuretics, or any over-the-counter drugs.

On clinical examination she was hypotensive and thought to have extracellular fluid (ECF) volume contraction. She was severely wasted and had proximal muscle weakness. Chest examination revealed tachypnoea and bilateral crackles.

Laboratory results on admission (Table I) revealed severe metabolic alkalosis, hypokalaemia, hyponatraemia, hypocalcaemia, hypomagnesaemia and hypophosphataemia.

Received 27 November 20 17; accepted 07 March 20 I8; published 17 March 2018. 
Blood glucose concentrations were normal. Urine chemistry revealed marked sodium and potassium wasting. Subsequent blood tests revealed acute kidney injury.

A clinical diagnosis of acute-on-chronic gastroenteritis was made, and she was admitted to hospital and initiated on intravenous isotonic fluids with replacement of her electrolytes. The acute kidney injury was ascribed to acute tubular necrosis (ATN) resulting from the hypovolaemia and the exposure to the nephrotoxic agent, kanamycin.

The combination of the metabolic alkalosis, hypokalaemia and renal wasting of sodium and potassium in the setting of ECF volume contraction led us to diagnose a Bartter-like syndrome, most likely also a result of kanamycin exposure.

This antibiotic was stopped on day 6. The patient's gastroenteritis responded well to treatment and her electrolytes gradually improved, but the respiratory symptoms worsened, and she eventually died.

\section{CASE 2}

A 20-year-old female presented with a 2-week history of constitutional symptoms, diarrhoea and abdominal cramps, without any vomiting. She received symptomatic treatment and was discharged to her local clinic for follow-up of laboratory results. There she was notified that she had tested positive for HIV-infection (CD4+ T-cell count was 53 I cells $/ \mathrm{mm}^{3}$ ) and pulmonary MDR-TB. She was started on MDR-TB treatment that included terizidone $750 \mathrm{mg} / \mathrm{d}$, ethionamide $750 \mathrm{mg} / \mathrm{d}$, ofloxacin $800 \mathrm{mg} / \mathrm{d}$, ethambutol $1000 \mathrm{mg} / \mathrm{d}$ and kanamycin $1000 \mathrm{mg} / \mathrm{d}$ IM, and anti-retroviral therapy which included tenofovir, lamivudine and efavirenz.

Fourteen weeks later she was readmitted, this time complaining of muscle cramps and lethargy. On examination she was not acutely ill, was normotensive and had a positive Chvostek sign. Laboratory tests revealed metabolic alkaIosis, hyponatraemia, hypokalaemia, hypocalcaemia, hypomagnesaemia and hypophosphataemia (Table I). The patient was admitted for electrolyte replacement and cardiac monitoring.

As the differential diagnosis included Fanconi syndrome secondary to tenofovir, this agent was replaced with zidovudine. However, the presence of metabolic alkalosis made the diagnosis of a proximal tubular lesion unlikely. Urine chemistry revealed wasting of potassium, phosphate and magnesium (Table I). A diagnosis of Bartter-like syndrome secondary to kanamycin was made and the drug was stopped without substitution. Her condition improved after oral and IV electrolyte replacement with resolution of her muscle cramps and weakness and no further complaints.

\section{CASE 3}

A 36-year-old female known with HIV (CD4+ T-cell count of 16 cells $/ \mathrm{mm}^{3}$ ) presented with a history of anorexia, weight loss and night sweats. A diagnosis of pulmonary MDR-TB was made, and she was started on moxifloxacin $400 \mathrm{mg} / \mathrm{d}$, ethambutol $800 \mathrm{mg} / \mathrm{d}$, teridizone $750 \mathrm{mg} / \mathrm{d}$, pyrazinamide I g/d, isoniazid 300 mg/d (KatG gene mutation was negative), pyridoxine $25 \mathrm{mg} / \mathrm{d}$ and kanamycin 1000 $\mathrm{mg} / \mathrm{d} \mathbf{I M}$. She was also known to suffer from major depression that was being treated with fluoxetine $20 \mathrm{mg} / \mathrm{d}$. She did not use diuretics. Three months following the initiation of MDR-TB treatment, owing to virological failure, she was started on second-line anti-retroviral therapy that included ritonavir-boosted liponavir, abacavir and lamivudine. Two months later, she developed Clostridium difficile-associated diarrhoea without any vomiting. The clinical examination did not indicate obvious ECF volume contraction. Laboratory tests revealed hyponatraemia, hypokalaemia, hypocalcaemia and hypophosphataemia (Table I). Urine tests revealed potassium, magnesium and phosphate wasting, as well as hypocalciuria.

Bartter-like syndrome was diagnosed, and the kanamycin was stopped without substitution. She received oral and intravenous electrolyte replacement and was treated for the pseudomembranous colitis with metronidazole, and later vancomycin. She responded to the treatment and was discharged to her local TB clinic for continuation of therapy.

\section{DISCUSSION}

Aminoglycosides are well known for their nephrotoxicity and commonly cause ATN, but may also cause renal tubular dysfunction that may manifest as Fanconi syndrome, distal renal tubular acidosis and Bartter-like syndrome [6]. Bartter-like syndrome secondary to aminoglycosides is an uncommon occurrence. Aminoglycosides that have been implicated in causing this syndrome include gentamicin [7], amikacin [8], tobramycin [7] and netilmicin [9].

There is variability in nephrotoxicity for different types of aminoglycosides. The most nephrotoxic of the aminoglycosides is neomycin followed by gentamicin, with streptomycin the least nephrotoxic [10]. Kanamycin has intermediate toxicity. This variability is partly related to the cationic charge that is generated by the number of amine groups attached to the drug $[\mathrm{I} \mid \mathrm{l}$.

Bartter syndrome may be inherited or acquired. In the case of aminoglycosides, it is thought to be a result of stimulation of the calcium-sensing receptor (CaSR) that is located on the basolateral surface of principal cells lining the thick ascending limb of the loop of Henle [12]. The CaSR is a unique cell surface receptor which does not have a single 


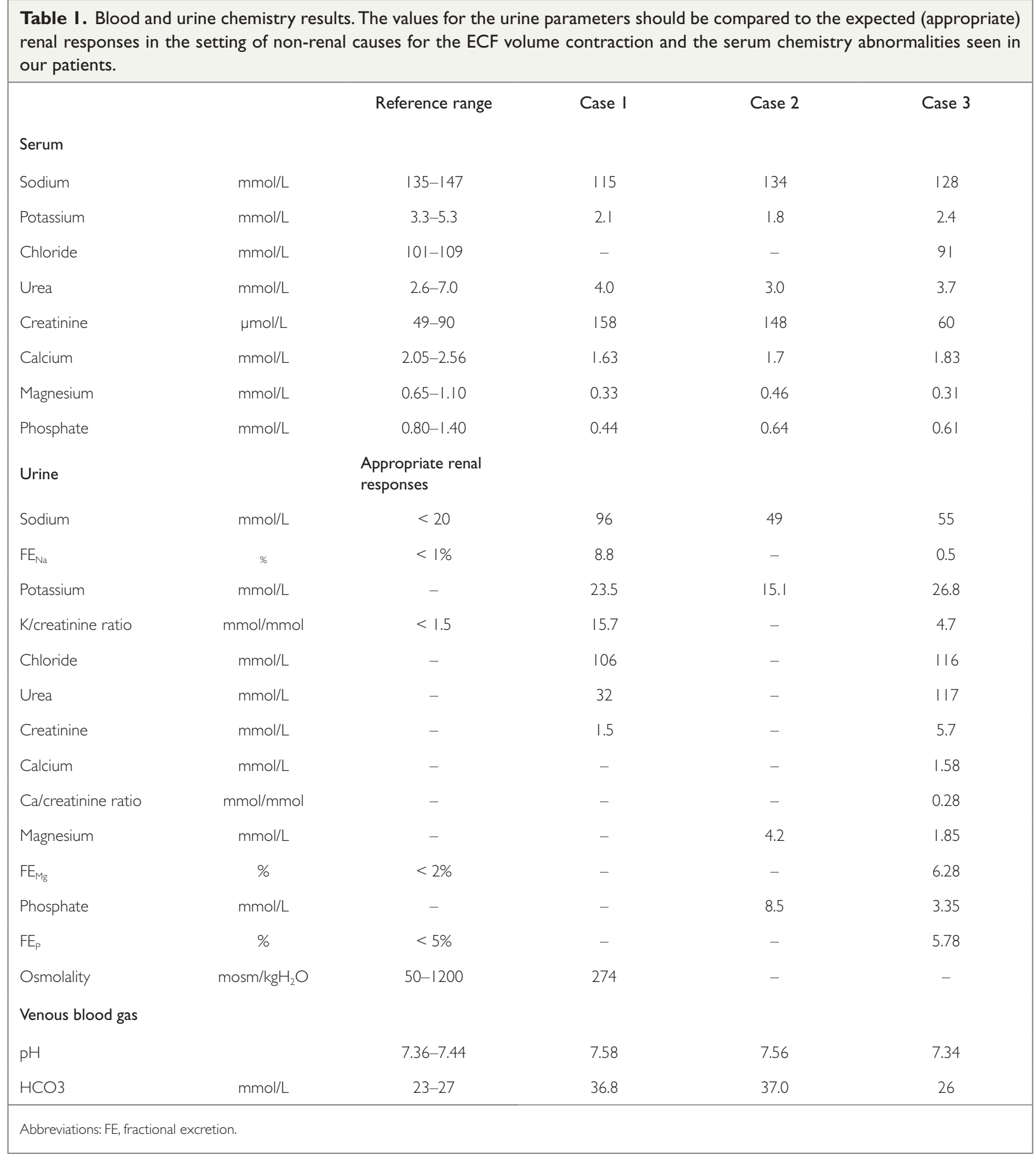

ligand but can be stimulated by numerous polyvalent cationic compounds, including aminoglycoside antibiotics. Stimulation of this receptor closes the rat outer medulla potassium (ROMK) channel located at the luminal surface, preventing potassium recycling. This has two effects: ( I) the sodium-potassium-2 chloride cotransporter (NKCC) ceases to function, and (2) loss of the lumen-positive charge prevents the normal paracellular reabsorption of sodium, magnesium and calcium (Figures IA and IB). The hypophosphataemia which was present in our cases may have been a consequence of malnutrition and/or renal losses due to a partial Fanconi's syndrome and/or high tubular flow due to the diuretic effect of kanamycin.

The South African guidelines for the treatment of MDRTB ranks aminoglycosides as the preferred bactericidal injectable antibiotic and recommends 4-6 months of therapy during the intensive phase of treatment [13]. An interesting finding in our cases is that the route of administration for kanamycin was intramuscular. The other case reports for aminoglycoside-induced Bartter-like syndrome reported intravenous routes of administration. 

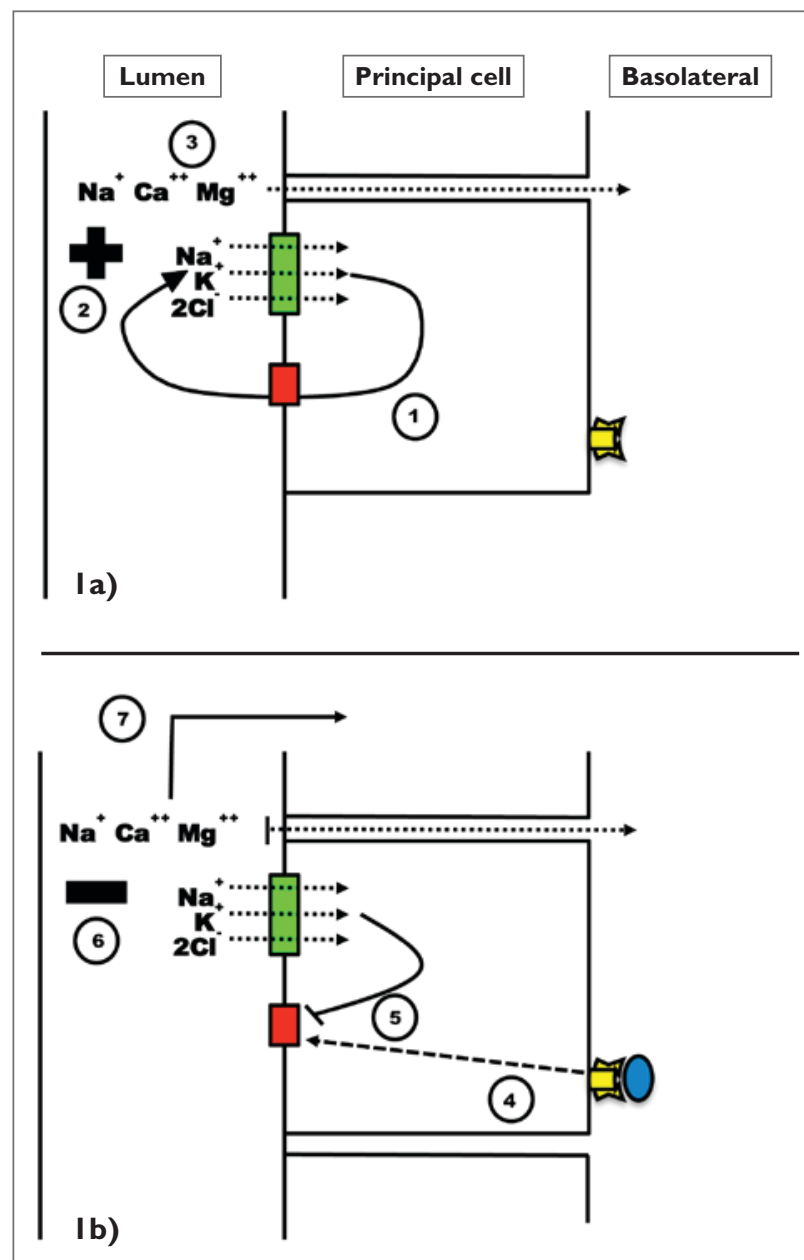

Figure I. Electrolyte reabsorption in the thick ascending limb of the loop of Henle.

Ia: (I) Entry of sodium, potassium and chloride into the principal cell through the $\mathrm{Na}-\mathrm{K}-\mathrm{Cl}$ cotransporter (NKCC, in green) with recycling of potassium through the rat outer medulla-K (ROMK) channel (red). (2) The recycling of $K$ induces a lumen-positive charge that (3) facilitates the paracellular reabsorption of cations.

Ib: (4) A cationic ligand (blue) binding to the calcium-sensing receptor (yellow) results in the closure of ROMK (5). The inhibition of $\mathrm{K}$ recycling and (6) the loss of the lumenpositive charge causes reduced transport through NKCC as well as via the paracellular route with subsequent urinary excretion of cations and anions.

With South Africa having one of the highest burdens of MDR-TB in the world, the use of aminoglycosides for this indication is expected to continue [14]. Newer drugs, such as bedaqualine [15], are now becoming available as part of the armamentarium for the treatment of MDR-TB and may replace aminoglycosides in the future, reducing the risk of this dangerous treatment-related complication.

\section{CONCLUSIONS}

To the best of our knowledge, these three cases represent drome. Asymptomatic MDR-TB patients who are receiving treatment that includes an aminoglycoside should be screened routinely for electrolyte disorders, and those presenting with muscle weakness and lethargy should be investigated for the possibility of aminoglycoside-induced Bartter-like syndrome.

\section{Ethics approval}

Approval for publication was granted by the Human Research Ethics Committee of Stellenbosch University (HREC reference number $\mathrm{CI} / \mathrm{I} / \mathrm{I} / 0 \mathrm{I} 7$ ).

\section{REFERENCES}

I. Bartter FC, Pronove P, Gill JR, MacCardle RC. Hyperplasia of the juxtaglomerular complex with hyperaldosteronism and hypokalemic alkalosis. A new syndrome. Am J Med. 1962; 33:8I I-828.

2. Hebert SC. Bartter syndrome. Curr Opin Nephrol Hypertens. 2003; 12:527-532.

3. Kennedy JD, Dinwiddie R, Daman-Willems C, Dillon MJ, Matthew DJ. Pseudo-Bartter's syndrome in cystic fibrosis. Arch Dis Child. 1990; 65:786-787.

4. Sekine K, Kojima I, Fujita T, Uchino K, Isozaki S, Ogata E. Factitious Bartter's syndrome induced by surreptitious intake of furosemide. Endocrinol Jpn. 1982; 29:653-657.

5. Lieber $\mathbb{H}$, Stoneburner SD, Floyd M, McGuffin WL. Potassiumwasting nephropathy secondary to chemotherapy simulating Bartter's syndrome. Cancer. 1984; 54:808-810.

6. Wargo KA, Edwards JD. Aminoglycoside-induced nephrotoxicity. J Pharm Pract. 2014; 27:573-577.

7. Geara AS, Parikh A, Rekhtman Y, Rao MK. The Case / Metabolic alkalosis in a patient with cystic fibrosis. Kidney Int. 2012; 81:421-422.

8. Chrispal A, Boorugu H, Prabhakar A, Moses V. Amikacin-induced type 5 Bartter-like syndrome with severe hypocalcemia. J Postgrad Med. 2009; 55:208.

9. Sandal G, Akbay Senay, Ozen M. Acquired Bartter-like syndrome association with netilmicin therapy in an extremely low birth weight infant. Ren Fail. 2014; 36:123-125.

10. Humes HD. Aminoglycoside nephrotoxicity. Kidney Int. 1988; 33:900-91।.

I I. Chiu PJS, Miller GH, Long JF, Waitz JA. Renal uptake and nephrotoxicity of gentamicin during urinary alkalinization in rats. Clin Exp Pharmacol Physiol. 1979; 6:317-326.

12. McLarnon S, Holden D, Ward D, Jones M, Elliott A, Riccardi D. Aminoglycoside antibiotics induce $\mathrm{pH}$-sensitive activation of the calcium-sensing receptor. Biochem Biophys Res Commun. 2002; 297:7I-77.

13. Management of drug-resistant tuberculosis. South African Department of Health. 2013. https://www.health-e.org.za/ wp-content/uploads/2014/06/MDR-TB-Clinical-GuidelinesUpdated-Jan-20। 3.pdf

14. Guidelines: Management of drug-resistant tuberculosis. South African Department of Health. Accessed March 2018. https://www.health-e.org.za/2014/06/19/guidelines-managementdrug-resistant-tuberculosis/.

15. Diacon AH, Pym A, Grobusch MP, de los Rios JM, Gotuzzo E, Vasilyeva I, et al. Multidrug-resistant tuberculosis and culture conversion with bedaquiline. N Engl J Med. 2014; 371:723-732. 